\title{
PENGEMBANGAN USAHA MIKRO, KECIL, DAN MENENGAH MELALUI FASILITASI PIHAK EKSTERNAL DAN POTENSI INTERNAL
}

\author{
Akmal fadilah, Alma nur'azmi Syahidah , Aris Risqiana, Ayu sofa Nurmaulida, \\ Dewi Dara Masfupah, Cucu Arumsari* \\ Universitas Muhammadiyah Tasikmalaya, Indonesia \\ *cucu.arumsari@umtas.ac.id
}

\begin{abstract}
Development of Micro, Small, and Medium Enterprises (MSMEs) Throug Facilitation of External Parties and Internal Potentials (Case Study in Group 1 "Kue Kijing" in Cimahi Hamlet. Bolang Village, Dayeuhluhur District).Internal development of the "Kue kijing" business group in increasing potential by using initial capital, innovating for its production, expanding marketing networks, and completing business facilities and infrastructure. In addition, facilitation from the SME's in Dayeuhluhur Sub-district has provided MSMEs access to marketing sources, conducting product promotion activities, expanding product marketing, and providing facilities and infrastructure. However, some entrepreneurs are constrained by rising prices of raw materials, limited human resources, problems with capital, lack of facilities and infrastructure and lack of access to product marketing.
\end{abstract}

Keywords:UMKM; potentialinternal

\begin{abstract}
Abstrak
Pengembangan secara internal dari kelompok usaha "Kue kijing "dalam meningkatkan potensi dengan cara menggunakan modal awal ,melakukan inovasi untuk hasil produksinya, memperluas jaringan pemasaran, dan melengkapi sarana dan prasarana usahanya. Selain itu, fasilitasi dari pihak UKM Kecamatan Dayeuh luhur telah memberikan akses UMKM terhadap sumber - sumber pemasaran, mengadakan, kegiatan promosi produk, memperluas pemasaran produk, serta menyediakan sarana dan prasarana. Namun beberapa pengusaha terkendala dengan meningkatnya harga bahan baku, keterbatasan sumber daya manusia, memiliki permasalahan dalam permodalan, kurangnya sarana dan prasarana serta kurangnya akses pemasaran produk.
\end{abstract}

Kata kunci: UMKM; potensi internal

\begin{tabular}{l|l|l} 
Submitted: $2021-09-25$ & Revised: $2021-10-21$ & Accepted: 2021-10-26
\end{tabular}

\section{Pendahuluan}

UKM sudah jelas dilindungi Negara dalam pegortasiannya hal ini salah satunya dapat dilihat Berdasarkan Keputusan Presiden RI Nomor 99 Tahun 1998, UKM adalah rakyat berskala kecil dengan bidang usaha yang secara umum merupakan kegiatan usaha kecil dan perlu dilindungi untuk mencegah persaingan usaha yang tidak sehat (Akifa, 2014).

UKM termasuk didalamnya adalah semua pedagang kecil dan menengah, penyedia jasa kecil dan menengah, petani dan peternak kecil dan menengah, kerajinan rakyat dan industri kecil, dan lain sebagainya, misalnya warung di kampungkampung, toko kelontong, koperasi serba usaha. Koperasi Unit Desa (KUD), toko serba ada wartel, ternak ayam, sebagainya (Robiyanto, 2004).

Di Kecamatan Dayeuhluhur khususnya di Dusun Cimahi banyak berkembang usaha dengan jenis olahan dan skala usaha yang beragam, sehingga Dayeuh luhur merupakan tempat tumbuhnya berbagai macam bentuk industri yang salah satunya usaha "Kue Kijing" yang ada di Dusun Cimahi yang letaknya di Desa Bolang Kecamatan Dayeuh luhur. Berdasarkan data dari Dinas dan UKM terdaftar jumlah pengusaha "Kue Kijing" sebanyak 1 unit.Industri ini mengolah bahan tepung tapioca dan terigu menjadi Kue Kijing. Jenis usaha inilah yang menjadi produk unggulan Desa Bolang" ini sangat berpotensi untuk meningkatkan perekonomian rakyat karena pada dasarnya bahan bakunya sangat banyak dipasaran dan di toko.

Ada beberapa kendala yang dihadapi oleh kelompok usaha "Kue Kijing" dalam pengembangan usahanya. Hal inilah yang menjadi pertimbangan untuk melakukan Pengabdian masyarakat ini.Permasalahan yang paling mendasar dihadapi oleh pelaku UMKM ini meliputi, sumber daya 
manusia yang kurang memiliki ilmu pengetahuan dan keterampilan dalam pengembangan usahanya, memiliki permasalahan dalam permodalan, kurangnya sarana dan prasarana, serta kurangnya akses pemasaran produk.

Hal tersebut didukung pendapat Wahyuningsih (2009) yang menyatakan UKM terbanyak bergerak pada bidang perdagangan besar dan eceran. Kegiatan ini banyak digeluti karena mudah melakukan, tidak membutuhkan modal yang besar, tidak memerlukan tempat khusus dan tidak memerlukan administrasi pengurusan usaha. UKM yang paling sedikit, bergerak pada bidang usaha listrik dan air bersih, ini disebabkan untuk usaha tersebut biasanya telah dilakukan oleh pemerintah daerah, karena bidang usaha tersebut memerlukan ketrampilan, permodalan dan peraturan khusus yang lebih besar serta rumit dibandingkan kegiatan perdagangan.

Beberapa permasalahan diatas inilah yang memerlukan perhatian yang lebih dari pemerintah daerah Desa Bolang khusunya Dinas Koperasi dan UKM Kabupaten Cilacap agar UMKM dapat tumbuh dan berkembang dengan lebih baik. Keberadaan UMKM ini Perlu untuk dikembangkan karena pengembangan ini akan berpengaruh penting terhadap peningkatan perekonomian masyarakat untuk mencapai kesejahteraan.

Pengabdian masyarakat ini bertujuan untuk mengetahui,mendeskripsikan dan meng-analisis pengembangan Usaha Mikro, Kecil, dan Menengah (UMKM) melalui fasilitasi pihak eksternal dan potensi internal pada kelompok usaha "Kue Kijing" di Dusun Cimahi Desa Bolang Kabupaten Cilacap dan untuk mengetahui, mendeskripsikan dan menganalisis kendala dalam pengembangan Usaha Mikro,Kecil,dan Menengah (UMKM) pada kelompok usaha "Kue Kijing" di Dusun Cimahi Desa Bolang Kabupaten Cilacap.

\section{Metode}

Pengabdian masyarakat ini mengutamakan penggunaan metode yang sesuai dengan pokok permasalahan dalam Pengabdian masyarakat yang dilakukan, agar diperoleh data yang relevan untuk dibahas lebih lanjut.Pengabdian masyarakat ini dimaksudkan untuk memperoleh gambaran secara menyeluruh mengenai pengembangan Usaha Mikro, Kecil,dan Menengah (UMKM) melalui fasilitasi pihak eksternal dan potensi internal pada kelompok usaha "KueKijing" di Dusun Cimahi Desa Bolang Kabupaten Cilacap. Jenis Pengabdian masyarakat yang digunakan dalam Pengabdian masyarakat ini adalah Pengabdian masyarakat deskriptif dengan pendekatan kualitatif.

Fokus dalam Pengabdian masyarakat ini yaitu :

1. Pengembangan Usaha Mikro, Kecil, dan Menengah (UMKM) melalui fasilitasi pihak eksternal dan pihak internal pada kelompok usaha "Kue Kijing" di Dusun Cimahi Desa Bolang Kabupaten Cilacap.

2. Pengembangan secara internal dari kelompok usaha "Kue kijing" didi Dusun Cimahi Desa Bolang Kabupaten Cilacap, diantaranya pengadaan packing, inovasi hasil produksi, dan perluasan jaringan pemasaran dengan adanya bazar di kecamatan dayeuh luhur.

3. Pengembangan secara eksternal dengan adanya bantuan dari Mahasiswa KKN ,diantaranya pemberian akses umkm terhadap sumber-sumber permodalan, peningkatan promosi produk, dan perluasan pemasaran produk.

4. Kendala dalam pengembangan Usaha Mikro, Kecil, dan Menengah (UMKM) yang dilakukan oleh kelompok usaha "Kue Kijing" di Dusun Cimahi Desa Bolang Kabupaten Cilacap, meliputi Meningkatnya harga bahan baku dipasar; Sumber daya manusia yang terbatas; Memiliki permasalahan dalam permodalan; Kurangnya sarana dan prasarana; serta Kurangnya akses pemasaran produk.

Analisis data dalam Pengabdian masyarakat ini dilakukan dalam empat tahapan menurut Miles dan Huberman (1984) dalam Su-prayogo dan Tobroni (2001,h.192): 
1) Pengumpulan data, adalah proses mengumpulkan data digunakan untuk mendukung hasil Pengabdian masyarakat.

2) Reduksi data adalah proses pemilihan,pemusatan perhatian pada penye-derhanaan, transformasi data kasar yang muncul dari catatan-catatan lapangan.

3) Penyajian data adalah kegiatan penyajian sekumpulan informasi dalam bentuk teks naratif yang dibantu dengan metrik, grafik, jaringan ,tabel, dan bagan yang bertujuan untuk mempertajam pema-haman peneliti terhadap informasi yang diperoleh.

Penarikan kesimpulan adalah mencari arti, pola-pola, penjelasan, konfigurasi yang mungkin, alur sebab akibat, dan proposisi. Penarikan kesimpulan dila-kukan secara cermat dengan melakukan verifikasi berupa tinjauan ulang pada catatan-catatan lapangan sehingga data-data yang ada teruji validasinya.

\section{Hasil dan Pembahasan}

1. Pengembangan Usaha Mikro, Kecil, dan Menengah (UMKM) Melalui Fasilitasi Pihak Eksternal dan Potensi Internal pada Kelompok Usaha "KueKijing" di Dusun Cimahi Desa Bolang Kabupaten Cilacap

Pemerintah adalah organisasi yang memiliki kekuasaan untuk membuat dan menerapkan hukum serta undang-undang di wilayah tertentu. Ada beberapa definisi mengenai sistem pemerintahan. Pemerintah menetapkan peraturan perundangundangan dan kebijakan. Sesuai dengan amanat Ketetapan Majelis Permusyawaratan Rakyat Republik Indonesia Nomor XVI/MPRRI/1998 tentang Politik Ekonomi dalam rangkat Demokrasi Ekonomi Usaha Mikro Kecil dan Menengah perlu diberdayakan sebagai bagian integral ekonomi rakyat yang mempunyai kedudukan, peran, dan potensi strategis untuk mewujudkan struktur perekonomian nasional yang makin seimbang, berkembang, dan berkeadilan (UU UMK 2013).

Selain itu akan lebih maksimal UMK di dukung juga oleh PEMDA. Pemerintah Daerah (PEMDA) memiliki peran yang sangat strategis dalam menumbuh-kembangkan usaha kecil dan menengah (UKM) di daerah. Dengan karakteristiknya yang relatif aman dari faktor-faktor eksternal, seperti kondisi ekonomi global, karena lebih banyak mengandalkan sumber daya (bahan baku) di dalam negeri, UKM relatif lebih mudah dikembangkan (Kemendagri.go.id, 2021).

Hal ini sesuai seperti yang diungkapkan oleh PBB dalam (Luz.A. Einsiedel,1968,h.9) ,bahwa: "pembangunan masyarakat ,merupakan suatu "proses" dimana usaha-usaha atau potensi-potensi yang dimiliki masyarakat diintegrasikan dengan sumber daya yang dimiliki pemerintah,untuk memperbaiki kondisi ekonomi, sosial, dan kebudayaan, dan mengintegrasikan masyarakat didalam konteks kehidupan berbangsa, serta memberdayakan mereka agar mampu memberikan kontribusi secara penuh untuk mencapai kemajuan pada level nasional."

2. Pengembangan Secara Internal dari Kelompok Usaha "Kue Kijing" di Dusun Cimahi Desa Bolang Kabupaten Cilacap

Adapun potensi dan pengembangan Yang dilakukan oleh pengusaha "Kue Kijing"diDusun Cimahi terdiri dari Pengadaan permodalan, Inovasi hasil produksi, Perluasan jaringan pemasaran, Pengadaan sarana dan prasarana produksi

3. Pengembangan Secara Eksternal dengan Adanya Bantuan dari Kecamatan Dayeuh luhur dan KKN Kelompok 1

Peran pemerintah dalam rangka mengembangkan Usaha Mikro, Kecil, dan Menengah (UMKM) memang sangat di- perlukan. Karena UMKM merupakan salah satu usaha yang potensial untuk meningkatkan perekonomian serta meningkatkan kesejahteraan masyarakat. Sehingga perlu adanya pemberdayaan dari segi sumber daya manusia sampai pada pengadaan sarana dan prasarana. Selain itu, ada banyak manfaat dari adanya UMKM yaitu dapat menyerap banyak tenaga kerja serta mengurangi tingkat pengangguran. "Tujuan mulia yang ingin dicapai sektor publik, yaitu kesejahteraan sosial (social welfare) dengan sendirinya menuntut tata kelola 
pemerintahan yang baik (good governance). Saat ini tuntutan agar pemerintah mampu secepatnya merealisasikan pencapaian kesejahteraan sosial, semakin besar." (Keban, 2008, h.17-18).

Dalam hal ini peran Kecamatan merupakan kepanjangan tangan dari Pemerintah Daerah untuk membantu mengatasi permasalahan yang terjadi dalam pengembangan UMKM dalam hal produksi dan pengolahan, pemasaran, sumber daya manusia, serta desain dan teknologi.

1) Pemberian akses UMKM terhadap Sumber-Sumber Permodalan

Usaha Mikro, Kecil, dan Menengah pada umumnya mengandalkan pada modal sendiri dalam menjalankan usahanya,dan terkadang mereka terjebak dengan keterikatan rentenir mengingat masih rendahnya aksesbilitas terhadap sumber-sumber pembiayaan formal.

2) Peningkatan Promosi produk

Dalam hal ini kegiatan peningkatan promosi produk yang dilakukan oleh Kecamatan yaitu berupa kegiatan seperti bazar atau pameran UMKM yang diadakan ditempat keramaian seperti lapangan pada tanggal 09 Oktober 2021.Selain itu,kegiatan ini biasanya diadakan diluar kota bahkan sampai keluar pulau agar prodduknya bias berkembang sampai luar kota.

3) Perluasan Pemasaran Produk

Dalam hal ini kecamatan telah memberikan sarana dalam pemasaran produk yaitu dengan mengadakan kegiatan promosi produk. Saat ini dengan kecanggihan teknologi, pemasaran dapat dilakukan menggunakan system online. Karena dengan internet jaringan pemasaran bias dijangkau hingga keluar negeri .Namun, hal ini kurang dipahami oleh para pengusaha Kue kijing karena factor pendidikan serta ilmu pengetahuan berbasise-bisnis yang masih rendah.

1. Kendala dalam pengembangan Usaha Mikro, Kecil, dan Menengah (UMKM) yang dilakukan oleh kelompok usaha "Kue Kijing" di Dusun Cimahi. Desa Bolang, Kecamatan Dayeuh luhur Meningkatnya Harga Bahan Baku

Bahan baku merupakan bahan pokok yang digunakan dalam mengolah suatu jenis bahan menjadi produk yang dapat dihasilkan dengan kreatifitas dan inovasi semaksimal mungkin. Kenaikan harga baku ini tentu saja mempengaruhi harga penjualan, apalagi bahan baku diperoleh dari supply, sehingga mereka memerlukan biaya yang lebih dibandingkan jika mendapatkan bahan baku dari kebun sendiri. Inilah yang menjadi kendala karena mereka hanya akan mensuplai bahan baku sesuai budget yang mereka miliki. Otomatis produksi yang dihasilkan akan terbatas padahal permintaan pasar cukup banyak.

2. Sumber Daya Manusia yang Terbatas

Sumber daya manusia adalah aspek terpenting dalam melakukan usaha. Dari hasil Pengabdian masyarakat ,mayoritas ilmu pengetahuan serta keterampilan diturunkan dari generasi sebelumnya. Oleh karena itu dari segi kreatifitas mereka kurang bisa mengembangkan kemampuan yang dimilikinya.

3. Memiliki Permasalahan dalam Permodalan

Modal adalah factor terpenting dalam membuka usaha. Karena UMKM merupakan usaha rumahan yang mengandal kan modal sendiri,maka dalam permodalan ini memerlukan bantuan dari pemerintah. Pengusaha Kue Kijing di Dusun Cimahi Desa Bolang,Kecamatan Dayeuh luhur mengaku bahwa mereka menggunakan modal dari tabungan sendiri. Walaupun untuk awal pengumpulan modal mereka sangat kesulitan.

4. Kurangnya Sarana dan Prasarana

Sarana dan prasarana merupakan hal penting dalam menunjang pengembangan UMKM. Karena itu, sarana dan prasarana dalam melakukan usaha harus mendukung. Seperti sarana dalam pemasaran produk atau sarana dalam proses pembuatan produk. Pengusaha Kue Kijing mayoritas sudah memiliki tempat untuk pemasaran produk kemasan.

Senada dengan pendapat Imron (2009). Menyatakan kelompok usaha mikro kecil menengah memiliki akses yang sangat terbatas bahkan tidak memiliki akses keuangan dalam pengembangan usahanya. Anggota kelompok ini biasanya bergerak pada daratan informal yang dengan sendirinya 
sangat labil. Mereka yang termasuk di dalamnya meliputi: 16 a. Para petani (nelayan dan peternak) b. Pedagang kaki lima (pedagang asongan) c. Pengusaha rumahan (pengusaha makanan dan penjahit).

\section{Kesimpulan}

Pengembangan secara internal dari kelompok usaha dalam meningkatkan potensi serta kemajuan usahanya dilakukan dengan beberapa cara,antara lain (1) Pengadaan permodalan, mayoritas pengusaha memulai usahanya menggunakan modal dengan tabungan sendiri; (2) Perluasan jaringan pemasaran, dengan caraonline; (3) Pengadaan sarana dan prasarana produksi,untuk awal dalam membuka usaha alat-alat yang digunakan sebagai proses produksi diperoleh dengan melakukan kredit kepihak lain disebabkan mahalnya harga barang dan minimnya modal karena modal didapat dari tabungan sendiri; dan (4) Pengembangan secara eksternal dengan adanya bantuan.

Dalam meningkatkan pemasaran produk, Kecamatan telah membantu dalam mempromosikan produk UMKM dengan cara mengadakan pameran atau bazar secara gratis bagi pengusaha dengan diwakilkan oleh kelompok KKN. Dalam meningkatkan perluasan jaringan pemasaran produk agar dapat mengembangkan UMKM, telah mengupayakan dengan mengadakan kegiatan promosi produk seperti mengadakan pameran atau bazaar.

\section{Daftar Pustaka}

Akifa P. Nayla. (2014). Komplet Akuntansi untuk UKM dan Waralaba. Jogjakarta: Laksana

Einsiedel,Luz,A.(1968). Success and Failure of some Community Development in Batang gas.University of the Philippines.Acommunity Development Research Counsiel Publication.

Hafsah,M.Jafar.(2004). Upaya Pengembangan Usaha Kecil Dan Menengah (UKM). http://keuda.kemendagri.go.id/artikel/detail/40-peran-pemda-dalam-tumbuhkanukm diunggah pada tanggal 24 September 2021.

Keban,YaremisT.(2008). Enam Dimensi Strategis Administrasi Publik:Konsep Teori dan Isu. Jakarta.Gavamedia.

Muhammad Ali Imron. (2009). Peran Baitul Maal Wattamwil (BMT) terhadap Pengembangan Usaha Mikro Kecil Menengah di Desa Wates Kecamatan Undaan Kabupaten Kudus. Skripsi STAIN Kudus

Pemerintah Kota (2011). Profil Kota Malang. www.malangkota.go.id.

Febra Robiyanto. (2004). Akuntansi Praktis untuk Usaha Kecil dan Menengah. Semarang: Studi Nusa.

Suharto,Edi (2009). Membangun Masyarakat Memberdayakan Rakyat: Kajian Strategis Pembangunan Kesejahteraan Sosial Dan Pekerjaan Sosial. Bandung,PT Refika Aditama.

Sri Wahyuningsih. (2009). Peran UKM dalam Perekonomian Indonesia: Jurnal Mediargo.Vol. 5, No.1.

Suprayogo,Imam,dan Tobroni (2001). Metodologi Pengabdian masyarakat Sosial-Agama. Bandung.Remaja Rosda karya.

Undang-undang Nomor 20 Tahun 2008 tentang Usaha Mikro,Kecil,dan Menengah.

Undang-Undang Usaha Mokro Kecil dan Menengah. (2013). Pustaka Mahardika: Yogyakarta 